\title{
EDUCAÇÃO ARTÍSTICA VERSUS EDUCAÇÃO ESTÉTICA NO ENSINO DO TEATRO?
}

Diogo José de Moraes Lopes Barbosa

Recebido em 19/06/2017

Aprovado em 22/09/2017 
Neste artigo, tentamos expor diferentes formas de ensino/aprendizagem do teatro, abordagens que contornam não apenas seu ensino no âmbito do fazer, das práticas de exercícios do aluno/ator, mas, sobretudo, das práticas de fruição do teatro em sala de aula. Essas não se dão apenas em aspectos ligados à realização de jogos e em montagem de espetáculos no âmbito escolar. O aluno aprende teatro também por outros vieses e através de outros elementos da cena, como a indumentária, os cenários, a iluminação, o texto. Assim, apresentaremos, no decorrer deste texto, possíveis abordagens na Pedagogia do Teatro, que tentam lidar com a aprendizagem da cena a partir de uma visão mais ampla.

Palavras-Chave: Pedagogia do Teatro; Educação Artística; Educação Estética.

\section{Apresentação}

$\mathrm{O}$ aprendizado das técnicas teatrais para a cena é uma prática que acontece na história da humanidade há muitos séculos. Ainda na Grécia Antiga os atores eram preparados para as apresentações nos festivais atenienses. O que se conhece de tais práticas é muito pouco, já que o material que chegou até nós hoje é muito escasso. Das peças escritas, contamos com pouco mais de vinte textos, contudo, os historiadores do teatro nos apontam alguns caminhos.

Sabemos que os atores já naquela época vestiam indumentárias volumosas para que fossem mais visíveis no palco, recitavam os textos dramáticos dos poetas individual e coletivamente (através do coro) e viviam os personagens das tragédias, comédias e tragicomédias em disputas ocorridas periodicamente, que perduravam um dia inteiro. Todos esses indícios nos levam a pensar também que já neste tempo se fazia necessária uma formação, alguma forma de educação para exercer tais funções na sociedade grega. Assim, por que não pensar em uma pedagogia da cena já nos primórdios do teatro?

Apesar de se tratar de um tema interessante, o que pretendemos discutir aqui não é a formação do ator profissional na origem histórica de seu ofício, tão pouco, sua preparação para o mercado contemporâneo. Vamos discorrer neste artigo questões acerca do ensino/aprendizagem da interpretação cênica e dos elementos do teatro, ambos no contexto escolar, ou seja, na formação básica da criança e do adolescente.

Como sabemos, o ensino de arte é obrigatório e deve estar presente no ensino fundamental e médio. Esse processo de partilha de conhecimento deve contemplar quatro linguagens artísticas diferentes, e uma delas é o teatro. 
O ensino de arte é obrigatório enquanto atividade na escola desde o início da década de 1970 no Brasil. Em 1996 ele se torna obrigatório enquanto componente curricular, ou seja, uma disciplina própria com conteúdos, avaliações e professores com formação específica. Em 2016, a Lei 13.278 avançou em mais tópicos sobre o ensino de arte, trazendo a obrigatoriedade das quatro linguagens (artes visuais, música, dança e teatro).

Para os professores de arte que atuam em escolas há muito anos, o ensino do teatro na escola não é novidade, no entanto, muitos poderiam se esquivar dos conteúdos inerentes às artes cênicas. Com a Lei citada, ao menos no plano hipotético, isto não pode mais acontecer. Daí nos parece pertinente levantar uma questão, sobretudo, sobre aqueles professores advindos de outras áreas artísticas que não são a do teatro: o que devemos ensinar aos alunos sobre a arte teatral?

Para alguns professores com formação em artes cênicas ou teatro, uma forma possível de ensinar o objeto em questão é através de atividades práticas da cena. Um professor, ou mesmo um diretor, tentará realizar um processo de ensino/aprendizagem em teatro conduzindo seu aluno a pisar em um palco (ou qualquer espaço que seja tratado como tal).

Aprender a arte da cena, para muitos, consiste em executar exercícios de improvisação cênica, decorar diálogos ou marcações, expor suas performances para os espectadores a sua volta. Será que a única prática pedagógica possível neste campo é esta? Para aprender teatro é necessário fazer teatro? Isto no sentido de passar pelas mesmas vivências que um futuro ator profissional passa. Ou existem outras opções, metodologias e abordagens?

No decorrer do texto, iremos desenvolver este pensamento, não com intenção de encontrar respostas exatas, mas, justamente, de problematizar e nos fazer pensar sobre nossas práticas enquanto professores e estudantes da arte teatral.

\section{PEQUeno RELATO PESSOAL}

$\mathrm{N}$ as décadas de 1980 e 1990, da mesma forma que aconteceu com muitos estudantes da educação básica, não tive aulas de educação artística centradas nas artes cênicas. No entanto, meu primeiro encontro com o teatro enquanto estudante de artes dramáticas, aconteceu na escola. A instituição na qual tive minha formação educacional, o Colégio Bairro Novo na cidade de Olinda, Pernambuco, mantinha um grupo teatral. Nele, os encontros e ensaios ocorriam no contra turno das aulas convencionais e as dinâmicas aconteciam em um pequeno auditório. 
Este local funcionava como espaço para aulas de disciplinas regulares, como matemática, língua portuguesa ou história, além de abrigar reuniões esporádicas de alguns eventos da escola. O professor responsável pelo processo pedagógico era um reconhecido diretor de teatro na cidade. Tinha bastante experiência como encenador, tendo já dirigido diversas peças em Recife, além de atuar também como professor universitário do curso de Licenciatura em Educação Artística com habilitação em Artes Cênicas da Universidade Federal de Pernambuco.

Aos alunos, era permitido que qualquer um participasse de forma regular, desde que o grupo não excedesse um quantitativo grande de estudantes. Em minha época, nunca havia mais do que doze estudantes.

As dinâmicas das aulas eram muito simples do ponto de vista de sua estruturação. Nos primeiros encontros, o diretor escolhia um texto de teatro para que fosse trabalhado e eram dadas a nós algumas opções, mas, ao final, ele "batia o martelo". Em continuação ao processo, líamos diversas vezes a obra dramatúrgica escolhida, começando com leituras brancas (sem grandes intenções quanto à interpretação dos personagens) passando para algumas formas mais elaboradas de apresentar os diálogos. Em seguida, marcávamos as cenas de acordo com o que nos era pedido pelo diretor, ou seja, ele nos posicionava no palco de acordo com as falas e os momentos do texto. Nesta etapa (a marcação), dávamos vida a toda a movimentação, criação gestual e corporal e ação física necessária à criação do espetáculo. Ao final, apresentávamos o resultado (a peça montada) nos meses de novembro e dezembro em eventos da própria escola. Este processo durava o ano letivo inteiro, resultando sempre em um espetáculo teatral.

Permaneci neste grupo por três anos. Após essa experiência ingressei no curso superior em teatro, encontrando novamente esse meu primeiro professor, agora em um ambiente acadêmico. Tive a oportunidade de trabalhar profissionalmente com ele fora da universidade e fui dirigido como ator em peças profissionais no mercado teatral recifense. Subitamente, neste processo já não educacional, me vieram à mente todos aqueles momentos de meus primeiros aprendizados em teatro ainda na escola. Também pude notar que aquele processo de ensino/aprendizagem da arte teatral não era tão diferente do método utilizado por ele de nos dirigir enquanto profissionais.

Nunca discuti o valor pedagógico daquelas práticas. Pelo contrário, afinal, muito provavelmente, sou professor e estudante de artes cênicas hoje, graças àquele meu primeiro contato. Contudo, neste momento, tenho consciência de que existem diversos caminhos para que um aluno possa ter acesso a uma boa educação em teatro. Creio que estudar o espetáculo em uma perspectiva do fazer, apenas, não é a única alternativa, e talvez nem a melhor. 


\section{EDUCAÇÃO ARTÍSTICA VERSUS EDUCAÇÃO ESTÉTICA?}

credito que as experiências descritas na sessão anterior, talvez
possam ser compartilhadas por muitas pessoas, cujo aprendizado
de teatro na escola teve como característica principal o viés do fazer. Poderíamos dizer que tais procedimentos pedagógicos seriam herança dos movimentos da Escola Nova, oriundos das escolinhas de arte da década de 1950. Nestes ambientes de ensino, os exercícios propostos para os alunos estavam focados quase que em absoluto na prática, como é mostrado no texto abaixo:

$\mathrm{Na}$ Escola Nova, o professor utiliza encaminhamentos que consideram o ensino e a aprendizagem basicamente como um processo de pesquisa individual ou no máximo de pequenos grupos. Os seguidores do filósofo americano John Dewey (1859-1952) procuram aprofundar suas ideias, partindo de problemas ou assuntos de interesse dos alunos, para assim desenvolver as experiências cognitivas, "num aprender fazendo" (FERRAZ; FUSARI, 2010, p. 29).

Tais fundamentos eram experienciados em aulas de artes plásticas. No entanto, é fácil pensar que o movimento teria exercido influência também na Pedagogia do Teatro, afinal, o pensamento de Dewey e dos "escola novistas" inspiraram diversas áreas nos meios educacionais. Quando o único contato do aluno com o teatro acontece em sala de aula, nas vivências de seu grupo, sem jamais assistir a espetáculos em teatros ou outros ambientes, podemos perceber uma postura metodológica modernista de ensino da arte. $\mathrm{Na}$ metodologia modernista, os alunos eram estimulados a produzir desenhos e pinturas sem ter contato com obras de artistas. O único referencial de arte que eles tinham era a própria criação produzida por eles. $\mathrm{O}$ mesmo pode acontecer em aulas de teatro.

Sabemos, contudo, que a natureza do espetáculo cênico é bastante diferente das artes visuais. Quando se popularizaram as primeiras técnicas de reprodutibilidade contemporâneas, os textos, as imagens, até os sons, puderam ser disseminados com maior facilidade, tornando acessível à população uma série de obras de artes. Benjamin, em seu ensaio A Obra de Arte na Era de Sua Reprodutibilidade Técnica, descreve tais fenômenos:

Em sua essência, a obra de arte sempre foi reprodutível. O que os homens faziam sempre podia ser imitado por outros homens. Essa imitação era praticada por discípulos, em seus exercícios, pelos mestres, para a difusão das obras, e finalmente por terceiros, meramente interessados no lucro. Em contraste, a reprodução técnica da obra de arte representa um processo novo, que se vem desenvolvendo na história intermitentemente, através de saltos separados por longos intervalos, mas com intensidade crescente (BENJAMIN, 1994, p. 165). 
Desta forma, pinturas de artistas renascentistas, exemplares de romances de grandes escolas literárias, sinfonias do período clássico poderiam estar acessíveis aos estudantes, utilizando vários processos diferentes de reprodução.

Já o teatro, por se constituir como arte presencial e irreprodutível, demonstra uma maior dificuldade de ir ao encontro do espectador. Enquanto a imagem da Mona Lisa, de Leonardo da Vinci, pode entrar em contato com o aluno através de uma fotocópia, Um Sonho de uma Noite de Verão, de William Shakespeare, enquanto espetáculo teatral, teria muita dificuldade em ter sua estrutura transportada para escolas, muitas vezes, gerando um processo oneroso (diversos atores, grandes cenários, uma complexa parafernália técnica de som e luz). Todas estas questões dificultam o acesso de alunos (e de um público em geral) à arte teatral, algo que causa impacto nos aspectos estéticos (de fruição) da Pedagogia do Teatro.

Apesar disso, muitos pensadores do ensino do teatro entendem como fundamental o contato presencial da criança com o espetáculo. É mostrado a nós que "[...] aqueles habituados a frequentar salas de teatro, de cinema, e a ouvir histórias demonstram maior facilidade de conceber um discurso narrativo, de criar histórias, e de organizar e apresentar os acontecimentos da própria vida" (DEGRANGES, 2006, p. 23). Desta forma, a apreciação da obra cênica tem grande valor, também, nos aspectos práticos do processo de ensino/aprendizagem em teatro, pois o aluno ao desenvolver um exercício de improvisação, traria para o jogo referências não apenas da vida e do cotidiano, mas também do próprio signo teatral, ou seja, dos espetáculos que ele já assistiu.

No âmbito das abordagens da Pedagogia do Teatro na escola, não pretendemos, neste artigo, enfatizar um processo (fruição) em relação a outro (criação), tampouco acreditamos na proposta de suprimir o fazer teatral em sala de aula. Contudo, a tradição do ensino do teatro se voltou quase que unicamente à prática de exercícios corporais e improvisações para a cena.

Essa dicotomia do fazer/ver esteve evidente nos conceitos de educação artística versus educação estética surgidos na década de 1970 com a criação dos cursos superiores de artes no Brasil. Na "[...] educação artística nota-se uma preocupação somente com a expressividade individual, com técnicas, mostrando-se, por outro lado, insuficiente no aprofundamento do conhecimento da arte [...]" (FERRAZ; FUSARI, 2010, p. 19), enquanto que a educação estética "[...] diz respeito dentre outros aspectos, à compreensão sensível-cognitiva do objeto artístico inserido em um determinado tempo/ espaço sociocultural" (Ibid., 2010, p. 54).

Apesar disso, estamos em outros tempos. A educação em arte vem mudando e a própria terminologia, "educação artística", não existe mais no 
Brasil, sendo substituída pelo termo "Ensino de Arte" ou simplesmente, "disciplina de Arte". A mudança no nome não veio como um mero desejo infundado dos legisladores, mas como uma mudança ideológica no campo do ensino/aprendizagem da arte. O termo antigo estava impregnado de propostas tecnicistas, ressaltando a dinâmica da produção artística escolar como um fazer irracional.

Já a terminologia, Ensino de Arte, se coloca ao lado do movimento de arte/educação surgido no final dos anos de 1970. Tais mudanças sugerem uma renovação das formas de abordagem da arte na escola. Estas novas ideias, mostradas pela pesquisadora Ana Mae Barbosa e outros artistas, pesquisadores e professores, apontam em seus novos conceitos que o "[...] conhecimento de arte se organiza na inter-relação da história, da leitura da obra de arte e do fazer" (BARBOSA, 2010, p. 98). A esta forma de ensino, foi dado o nome de Abordagem ou Proposta Triangular, prática que liga os aspectos do fazer arte com os da fruição (leitura e contextualização).

Desta forma, a dicotomia do ver e do fazer teatro, antes mencionada, não se encaixa nas propostas contemporâneas de ensino da arte. Inicialmente, o título desse trabalho se apresentaria de maneira afirmativa, no entanto, nos processos de revisão, nós o transformamos em pergunta, já que as duas ações (o fazer e o fruir) não precisam e nem devem estar em oposição. Na verdade, elas devem ser complementares. O aluno aprende teatro em exercícios práticos de atuação e assistindo a espetáculos. Trata-se da junção das atividades de realizador e espectador, que dá uma formação completa ao estudante de teatro no contexto da escola.

\section{Outras alternativas Para uma Pedagogia do Teatro}

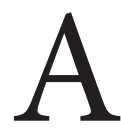

Abordagem Triangular, apesar de ser uma proposta desenvolvida no campo das artes visuais, foi perfeitamente aplicada em outras áreas do ensino artístico como a dança, o teatro e a música. Assim, é comum vermos professores de artes cênicas ou de educação musical utilizando-se de seus preceitos.

Nos aspectos da leitura e da contextualização, professores de teatro podem aplicar os conteúdos e realizar as dinâmicas na apreciação e na análise de elementos visuais da cena, como a indumentária, as maquiagens, a iluminação cênica. Esta ação pode ser realizada fazendo-se uso de fotografias e imagens de espetáculos encontradas em diversas mídias, como jornais, revistas, além da possibilidade da exibição de DVDs e dos registros audiovisuais do acervo de grupos e companhias teatrais.

É possível também propiciar o encontro do aluno com textos 
dramáticos diversos de autores clássicos e contemporâneos. Poucos são os estudantes que conhecem a obra dramatúrgica de Shakespeare, Ibsen ou Nelson Rodrigues. Mesmo autores de literatura infantil, como Maria Clara Machado, são desconhecidos nas escolas, sendo que aulas com análise ou leitura de tais materiais contemplam perfeitamente os conteúdos do ensino de teatro. Além disso, o ensino de aspectos da história mundial e brasileira da arte teatral também é ignorado, de forma que se fala, no máximo, sobre teatro grego. Quantos de nossos estudantes já ouviram falar de João Caetano, do Teatro Brasileiro de Comédia ou do Teatro de Arena?

Apesar da possibilidade do uso da Abordagem Triangular no campo da pedagogia do teatro, talvez pela especificidade da linguagem cênica, outras opções metodológicas, mais voltadas ao ensino desta arte, poderiam nos mostrar um caminho mais interessante no âmbito da fruição e da análise do espetáculo. O professor e pesquisador Luiz Reis, da Universidade Federal de Pernambuco nos aponta caminhos:

Procuro passar [...] a visão mais generosa possível de nossa arte, com potencial pedagógico em todos os seus campos de saber: no texto, na recepção, nos elementos visuais e sonoros da cena, na produção, na pesquisa etc. - e não somente no trabalho do ator. Reforço sempre a necessidade de inserir os alunos, desde muito cedo, numa ampla cultura teatral. Conceitos como dramaturgia, encenação ou crítica, por exemplo, podem ser trabalhados, com a devida adequação, até mesmo na Educação Infantil (REIS, 2014, p. 180).

Reis (2014) nos mostra essas possibilidades a partir do pensamento e da visão teórica do britânico David Hornbrook (1991) que indica três formas simultâneas de ensino do teatro: a criação, a execução e a recepção (making, performing, responding).

Ainda segundo Luiz Reis, a proposta britânica poderia ser comparada a nossa Abordagem Triangular em artes visuais, contudo, sendo esta primeira (a de Hornbrook) pensada exclusivamente para o ensino do teatro, pois, como afirma Reis, em "[...] Ana Mae, temos dois eixos mais ligados à recepção do fenômeno artístico (ler e contextualizar), enquanto Hornbrook defende dois eixos mais diretamente ligados à produção poética (criação, execução)" (Idem).

Podemos interpretar o trabalho de criação como algo realizado pelo artista: o encenador, o dramaturgo, e até mesmo o ator, desde que sua participação para realização de uma determinada obra tenha características autorais. Já a execução dela, pode não ter sido necessariamente realizada pelo seu criador.

É possível que o executor tenha habilidades e conhecimentos artísticos também, no entanto, sua participação é limitada à feitura dela. Apesar de a teoria de Hornbrook enfatizar os aspectos ligados ao fazer, 
vemos em tais formulações também uma preocupação no campo da formação pedagógica do espectador teatral, algo raramente proposto.

$\mathrm{Na}$ verdade, muitos pensadores não falam de abdicar totalmente a prática do fazer teatral em sala de aula, mas de agregar mais possibilidades de conhecimento (a fruição) à experiência de ensino/aprendizagem em teatro. Além disso, o fazer teatral não está ligado apenas à prática do ator, já que existem outros profissionais envolvidos na construção do espetáculo (encenadores, iluminadores, sonoplastas, figurinistas, cenógrafos), cujos trabalhos são tão ligados à criação artística quanto o ofício do ator ou da atriz.

Atividades em sala de aula - como o desenvolvimento de indumentária para personagens de histórias (contos de fada, romances da literatura brasileira), conhecidas pelos alunos, ou mesmo textos teatrais devem ser encaradas como fazer teatral no âmbito da escola. A confecção de maquetes de cenários em escala menor ou o manuseio de pequenos refletores com lâmpada dicroica são possibilidades a serem usadas com os alunos.

Outra opção se refere às leituras dramatizadas de textos teatrais, realizadas em sala de aula. Os estudantes, ao mesmo tempo em que atuam como fruidores da obra (leitores), também a executam. As possibilidades são muitas, de forma que não há necessidade de forçar um aluno inseguro a se expor contra sua vontade em um exercício de improvisação, muitas vezes sem fundamento.

\section{Considerações Finais}

or fim, podemos ressaltar que uma aprendizagem significativa em teatro, por parte do aluno, pode não acontecer, mesmo que haja atividades práticas com jogos e exercícios. Isto porque o estudante pode executar mecanicamente determinadas ações que o professor lhe pede, sem que aconteça uma conscientização corporal ou uma apropriação real do conteúdo proposto.

Neste caso, não existe trabalho artístico do ator/aluno, nem mesmo em uma produção profissional de teatro. Ele estará em cena meramente como um técnico, obedecendo às ordens de um encenador.

Isto era o que o teórico de teatro, Gordon Craig, esperava de suas marionetes humanas. Ao longo de sua história com o teatro, Craig levantou a ideia de que o ator era o elemento danoso à arte teatral, já que nunca obedecia às ordens dos diretores. Um ator sem autonomia não era um artista, mas sim, um robô programado. Não é isso, porém, que um professor deve esperar de seus alunos. Ao contrário, a arte na escola deve estimular os processos de expressão e criação. 
Desta forma, se existe uma vontade do professor e dos educandos de realizar um trabalho prático no âmbito do corpo, do gesto, da fala, ou seja, das ações do ator em cena, obviamente isso deve ser feito. Contudo, esta dinâmica deve acontecer com o intuito de possibilitar que o aluno tenha uma aprendizagem real em teatro e não apenas experiências vagas de ler um texto ou executar movimentos sem nenhuma reflexão sobre o ato.

Certamente, o papel do professor em todo esse processo é de extrema importância, pois ele é quem está próximo da turma e conhece suas necessidades. A condução dos jogos e exercícios de corpo e de cena é realizada pelo educador, assim como a escolha e a mediação das atividades de fruição. Porém, um professor com pouco preparo ou sem consciência do que está fazendo pode trazer para o aluno atividades muito pouco produtivas, seja no âmbito do fazer ou do ver.

Quando falamos de uma aprendizagem real, nos referimos a uma aprendizagem significativa, que irá fazer diferença na formação do aluno. Mesmo uma atividade de fruição, como um passeio a um teatro para assistir a um espetáculo, se a conduzida com pouca consciência pelo professor, pode se transformar em uma atividade meramente recreativa, em vez de ser um momento de grandes proveitos em termos pedagógicos.

Não temos a intenção, nesse trabalho, de sugerir atividades prescritivas em sala de aula, como fórmulas. Acreditamos que cada professor desenvolve suas próprias metodologias, de acordo com suas necessidades e com as de seus alunos. O que apontamos são possibilidades, dentre muitas, que possibilitam contemplar aquilo que defendemos: um ensino de teatro que abranja essa arte nos seus muitos aspectos.

Neste último exemplo, no passeio para assistir a um espetáculo, em um trabalho processual, em longo prazo, o professor pode mostrar quem escreveu o texto, em que momento histórico e espaço geográfico ele foi concebido, e explanar sobre o contexto no qual a obra foi criada.

Se a peça já tiver sido montada e existir algum material visual ou audiovisual, é interessante que o aluno possa ter acesso a eles antes de assistir ao espetáculo no teatro. Isto propiciará que o processo de ensino/ aprendizagem se torne mais rico, além de permitir que o aluno compreenda que o teatro é uma prática artística, mas também um bem cultural de sua comunidade, cidade ou país.

No caso de um texto que a turma esteja trabalhando para uma futura montagem pedagógica, quando o professor traz essas informações, ou quando ele estimula o aluno a buscar por elas, a turma compreende que o espetáculo que estão trabalhando foi montado por diversas outras pessoas no passado. A articulação entre estes diferentes aspectos no ensino do teatro (o passado e o futuro, o ver e o fazer) é que resultam em bases sólidas para a construção do conhecimento em arte. 


\section{REFERÊNCIAS}

BARBOSA, Ana Mae. A imagem no ensino da arte: anos oitenta e novos tempos. São Paulo: Perspectiva, 2010.

BENJAMIN, Walter. A obra de arte na era de sua reprodutibilidade técnica. In: Magia e técnica, arte e política: ensaios sobre literatura e história da cultura. São Paulo: Brasiliense, 1994, p. 165-196.

BRASIL. Lei de Diretrizes e Bases da Educação Nacional: Lei no ${ }^{\circ} 3.278$. Brasília: 2016.

BRASIL. Secretaria de Educação Fundamental. Parâmetros curriculares nacionais: arte. Brasília: MEC/SEF, 1997.

DESGRANGES, Flávio. Pedagogia do Teatro: provocação e dialogismo. São Paulo: Hucitec, 2006.

FERRAZ, Maria Heloísa C. de T.; FUSARI, Maria F. de Rezende e. Arte na Educação Escolar. São Paulo: Cortez, 2010.

HORNBROOK, David. Education in drama. London: The Farmer Press, 1991.

REIS, Luíz. E aí, girou? Uma Experiência em Pedagogia do Teatro Inspirada pelo Brinquedo Popular do Pião. Rascunhos Uberlândia, Minas Gerais, v. 1, n. 2, p. 169-180, jul./dez. 2014. 